\title{
薄層クロマトグラフィーによる合成保存料 およびズルチンの分析
}

(昭 和 40 年 10 月 18 日 受 理)

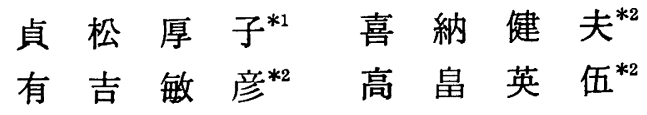

\author{
Detection of Food Preservatives and Dulcin by \\ Thin Layer Chromatography \\ Atsuko SADAMATSU*1, Takeo KINA*2, Toshihiko ARIYOSHI*2, \\ and Eigo TAKABATAKE*2
}

(*1Nagasaki Prefectural Public Health Laboratory: 128, Nakagawa-machi, Nagasaki ; *2Pharmaceutical Faculty, Nagasaki University:

4-23, Bunkyo-machi, Nagasaki)

\begin{abstract}
Thin layer chromatography was applied to the detection of benzoic, salicylic, dehydroacetic, and sorbic acids, ethyl, propyl and butyl esters of p-hydroxybenzoate and dulcin. Kieselgel $\mathrm{G}$ activated at $80^{\circ} \mathrm{C}$ for 30 minutes or Wakogel B-5 activated at $100^{\circ} \mathrm{C}$ for 30 minutes was used. For the detection of the spots, $1 \%$ ferric chloride solution, $0.1 \%$ bromcresolgreen alcohol solution and $1 \%$ potassium permanganate solution were successively sprayed. The chromatoplate was developed with chloroform-propionic acid ( $4: 1)$ mixture for the group separation of the esters, the acids and dulcin.

Chloroform-ethyl acetate $(9: 1)$ mixture was used for the separation of sorbic acid from benzoic acid and dehydroacetic acid, and also for the identification of esters (as $p$-hydroxybenzoic acid). The preservatives were clearly separated with $n$-heptane-propionic acid $(4: 1)$ mixture, by which the good separation of dehydroacetic acid from benzoic acid and sorbic acid has been achieved.
\end{abstract}

(Received October 18, 1965)

\section{緒言}

さまさまな食品に多種の食品添加物が使用されている 現在, その系統的簡易検出法の確立が望まれている. 合成保存料の検出には従来ペーパークロマトグラフィ -1) 4) および口紙電気泳動法が用いられ，最近薄層ク ロマトグラフィー5) 8)による検出法もいくつか報告さ れている. われわれも本法を用いて食品中の台成保存料 (安息香酸, サリチル酸, パラオキン安息香酸ならびに そのエステル類，デヒドロ酢酸，ソルビン酸）および合 成甘味料（ズルチン）について，これらの添加物が同時 に使用されている場合を考感して系統的に検出する方法 を検邻し，比較的良好な絬果を得たりで朝告する。

*1 長崳県衛生研究所：長岮市中川界了128

*2 長崎大学薬学部 : 長崳市文教町 4-23

\section{実験方法}

(1) 試 料

安息香酸 (BA と略記する. 以下同じ), サリチル酸 $(\mathrm{SA})$, パラオキシ安息香酸 $(\mathrm{PA})$, パラオキシ安息香 酸エチルェステル (PE), プロピルエステル $(\mathrm{PP}), \quad$ ブ チルエステル (PB), デヒドロ酢酸 (DHA), ソルビン酸 (SOA)，ズルチン (DLC) を用いた. BA および SA は 市販品 (一級) を水から 2 回, PA, PE, PP, PB, DHA, SOA (それぞれ一級品)およびDLC (添加物用) はェタ ノールから3回再結晶したものをそれぞれ $0.1 \%$ ェタ, ール溶液とした。

(2) 吸着剂

忣着剂A．キーゼルゲル G(メルク製，ギブス $13 \%$ )

$20 \mathrm{~g}$ に水 $40 \mathrm{ml}$ を加え激しく振りまぜ使用した。

吸着剂B．ワコーゲル B-5（和光純薬製・ギプス 5 
\%) $20 \mathrm{~g}$ に水 $30 \mathrm{ml}$ を加え激しく振りまぜ使用した.

Camag 製アプリケーターを用いて平滑なガラス板上 に厚さ約 $0.25 \mathrm{~mm}$ の吸着層を作り，30分放置後, 吸着剤 $\mathrm{A}$ では $80^{\circ}, 30$ 分, 吸着剤 Bでは $100^{\circ}, 30$ 分加熱し活性 化したプレートを使用した。

(3) 展開溶媒
I．クロロホルムープロピオン酸 $4: 1$
II. クロロホルムー酶酸ェチル $9: 1$
III. $n$-ヘプタンープロピオン酸 $4: 1$

(4) 展 開

試料の $0.1 \%$ エタノール 溶夜約 $5 \mu \mathrm{l}$ を下端より $3 \mathrm{~cm}$ のところに付し原点とし， $24 \mathrm{~cm} \times 11 \mathrm{~cm} \times 23 \mathrm{~cm}$ の展 開槽で上昇法により原点から約 $10 \mathrm{~cm}$ まで展開する. 展 開に要する時間は溶媒により差があるが30～50分（たと えば, 溶媒 I, 室温 $12^{\circ}$ で 35 分, 溶媒 II, $13^{\circ}$ で 40 分, 溶 媒正, $14^{\circ}$ で40分) を要する.

(5) 発色剂

(1) $1 \%$ 塩化第二鉄溶液

(2) $0.1 \%$ ブロムクレン゙ールグリーン (BCG)・エタ，
を滴加する.

(3) $1 \%$ 過マンガン酸カリウム溶液

\section{実駼結果}

1. 保存料およびズルチンの葶首クロマトグラフィー (1) 発色剂について

各試料を展開したプレートに，まず $1 \%$ 塩化第二鉄溶 液を噴霧すると， SA は特有の紫色を呈し，PA，DHA， SOA は多量に存在すれば黄色を，BA も淡かっ色を呈 する. つぎに BCG 溶液を噴第すると BA が暗かっ色 〜淡紫色を呈し，その上に続けて $1 \%$ 過マンガン酸カリ ウム溶液を噴蓩すると BA は消えて, 他の $\mathrm{PA}, \mathrm{PE}$, $\mathrm{PP}, \mathrm{PB}, \mathrm{DHA}$ ， SOA，DLC が黄かっ色を呈する。こ の場合, BA の検出に $\mathrm{BCG}$ 溶液を噴霧するので展開溶 媒に酸を用いたときにはプレートの酸を十分に揮散させ る必要がある．以上のように $1 \%$ 塩化第二鉄溶液， BCG 溶液および $1 \%$ 過マンガン酸カリウム溶液の順に噴罞す ることにより 1 枚のプレート上で同時に各種の添加物を 検出できる. 発色剤による呈色拀よびそれぞれの検出限 度を Table 1 に示す.

一ル溶液緑色を呈するまで希水酸化ナトリウム溶液

Table 1. Color of Spots of Food Preservatiyes and Dulcin on Thin Layer Plate

\begin{tabular}{|c|c|c|c|}
\hline $\begin{array}{c}\text { Food Preservative } \\
\text { and Dulcin }\end{array}$ & $1 \% \mathrm{FeCl}_{3}$ & $1 \% \mathrm{FeCl}_{3}, \quad 0.1 \% \mathrm{BCG}$ & $1 \% \mathrm{FeCl}_{3}, 1 \% \mathrm{KMnO}_{4}$ \\
\hline Benzoic acid & light brown & $\begin{array}{l}\text { dark brown } \\
\text { light purple }(50 \mu \mathrm{g})\end{array}$ & \\
\hline Salicylic acid & purple & purple & dark purple $(1 \mu \mathrm{g})$ \\
\hline Ethyl $p$-hydroxybenzoate & yellow* & & yellow brown $(0.5 \mu \mathrm{g})^{*}$ \\
\hline Propyl $p$-hydroxybenzoate & yellow* & & yellow brown $(0.5 \mu \mathrm{g})^{*}$ \\
\hline Butyl $p$-hydroxybenzoate & yellow* & & yellow brown $(0.5 \mu \mathrm{g})^{*}$ \\
\hline Dehydroacetic acid & yellow & & yellow brown $(1 \mu \mathrm{g})$ \\
\hline Sorbic acid & yellow & & yellow $(0.5 \mu \mathrm{g})$ \\
\hline Dulcin & & & yellow brown $(0.5 \mu \mathrm{g})$ \\
\hline
\end{tabular}

( ): The values shown in parentheses represent the minimum amount capable of being detected on thin layer plate

* Color of the spot of $p$-hydroxybenzoic acid obtained from the ester

(2) 展開溶媒について

i）溶媒Iを用いるとき (Fig. 1-a)：PA 以外の酸性 保存料 (BA, SA, DHA, SOA) は Rf 0.9 以上, パラ オキシ安息香酸およびそのェステル類 ( $\mathrm{PA}, \mathrm{PE}, \mathrm{PP}$, PB)は0.6〜0.8, ズルチンは0.4に大別して展開される.

ii）溶媒II を用いるとき (Fig.1-b，-c) : Fig.1-bに 示すように PA 以外の酸性保存料 (BA, SA, DHA, SOA) は tailing し分離困難であるが，Fig. 1-c にみら れるように吸着剤 B では, BA と SOA ならびに DHA と SOA がそれぞれよく分離される.このように同じ溶
媒を用いても吸着剤に含まれるギプスの含有量により保 存料の分離に著しい差が認められる.SA は特有の発色 のために容易にSOA と区別して検出でき,ズルチンはい ずれの場合も原点にとどまり他の保存料と分離しうる. エステル類のアルコール基の炭素数がますとともに, いずれの吸着剤でも Rf 值は大きくなるが，その差はさ ほど著しくはなく同定は困難である.

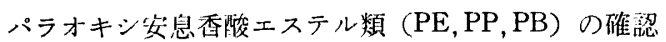
には,試料の一部を $10 \% \mathrm{NaOH}$ 溶液 $2 \sim 3 \mathrm{ml}$ に溶かし， 水を $3 \mathrm{ml}$ 加えて, 還流冷却器を付け石綿金網上で15分間 


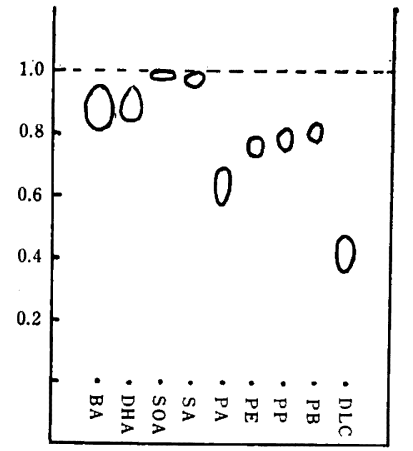

(a)

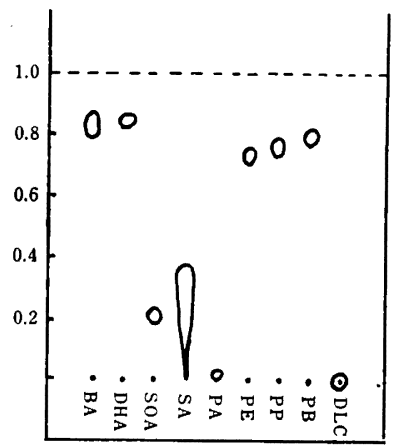

(c)

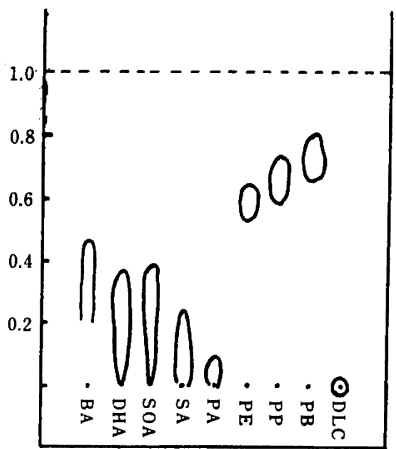

(b)

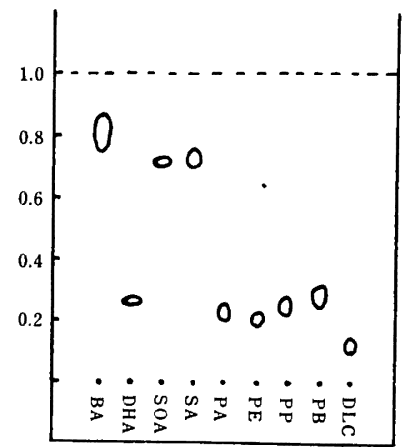

(d)

Fig. 1. Chromatograms of food preservatives and dulcin Adsorbent

(a) Wakogel B-5 (B)

(b) Kieselgel G (A)

(c) Wakogel B-5 (B)

Solvent

(d) Kieselgel G (A)

Chloroform-Propionic acid 4-1 (I)

Chloroform-Ethylacetate 9-1 (II)

Chloroform-Ethylacetate 9-1 (II)

$n$-Heptane-Propionic acid 4-1 (III)

BA; Benzoic acid

DHA; Dehydroacetic acid

SOA; Sorbic acid

SA; Salicylic acid

PA; $p$-hydroxybenzoic acid
PE ; Ethyl $p$-hydroxybenzoate

PP ; Propyl $p$-hydroxybenzoate PB; Butyl $p$-hydroxybenzoate DLC; Dulcin
煮沸し, 加水分解したのち, 希塩酸で酸性としェーテル 抽出し,エーテル留去後PA と並行して展開すればよい. ズルチンは原点にとどまり，他の物質と分離しうる. とくに PA の定性反応である Millon-Lintner 反応で ズルチンも紅色を呈し，PA の判定に困難であったが， 画者の分離に十分活用しうる.

iii）溶媒而を用いるとき (Fig. 1-d)：Fig. 1-d に示 すように，スポットが小さくまとまり，陵性保存料が淤 用されている場合，あるいは，酸性保存料からエステル 類またはズルチンを分離するのに比較的よい溶媒であ る.とくに $\mathrm{BA}$ と $\mathrm{DHA}$ ならびに $\mathrm{DHA}$ とOA の分離 によい.
以上の 2 種の吸着剤と 3 種の展開溶媒における展開値 をまとめると Table 2 のごとくになる.

\section{2. 食品中の保存料およびズルチンの分離検出法}

食品よりの抽出法

抽出法: 日本薬学会協定衛生試験法, 保存料試験法の 溶媒による抽出分離法に準じて,エーテル 50 〜 $100 \mathrm{ml}$ 用いて 1 回抽出した。得ら㧈たェーテル抽出液を水洗後 $1 \%$ 炭酸水素ナトリウム溶液 $20 \mathrm{ml}$ で 2 回抽出し酸性保 存料を抽出する.エーテル層をとりェーテルを留去し残 留物をフラクションXとする. 水層は塩酸酸性としェ一 テル $50 \mathrm{ml}$ で 1 回抽出し, 水洗し, エーテルを留去し残 留物をフラクションYとする. 
Table 2. Rf Values of Food Preservatives and Dulcin

\begin{tabular}{|c|c|c|c|c|}
\hline \multirow{2}{*}{$\overbrace{\text { Compound }}^{\text {Solvent*1 }}$ Adsorbent*2 } & I & \multicolumn{2}{|c|}{ II } & \multirow{2}{*}{$\begin{array}{l}\text { III } \\
\text { A }\end{array}$} \\
\hline & B & A & B & \\
\hline Benzoic acid & 0.87 & 0.42 & 0.83 & 0.82 \\
\hline Salicylic acid & 0.97 & 0.20 & 0.34 & 0.63 \\
\hline$p$-Hydroxybenzoic acid & 0.63 & 0.47 & 0.02 & 0.22 \\
\hline Ethyl $p$-hydroxybenzoate & 0.76 & 0.56 & 0.73 & 0.21 \\
\hline Propyl $p$-hydroxybenzoate & 0.78 & 0.61 & 0.76 & 0.25 \\
\hline Butyl $p$-hydroxybenzoate & 0.81 & 0.67 & 0.79 & 0.28 \\
\hline Dehydroacetic acid & 0.88 & 0.33 & 0.84 & 0.27 \\
\hline Sorbic acid & 0.99 & 0.35 & 0.22 & 0.72 \\
\hline Dulcin & 0.41 & 0 & 0 & 0.13 \\
\hline $\begin{array}{ll}* 1 & \text { I ; Chloroform-Prop } \\
\text { II ; Chloroform-Ethy } & \text { III } n \text {-Heptane-Propic } \\
\text { *2 } & \text { A ; Kieselgel G } \\
\text { B ; Wakogel B-5 }\end{array}$ & $\begin{array}{l}\text { (4:1) } \\
\text { d }(9: 1)\end{array}$ & & & \\
\hline
\end{tabular}

Sample

containing

BA, SA, PA, PE, PP, PB, DHA, SOA \& DLC

Aqueous solution

homogenized with water filtered or centrifuged

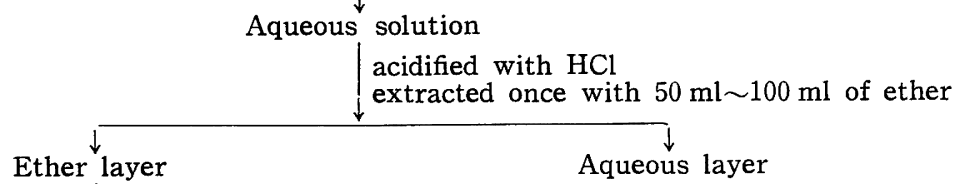

Ether layer $\begin{aligned} & \downarrow \\ & \downarrow \\ & \text { extracted twice with } 20 \mathrm{ml} \text { of } 1 \% \mathrm{NaHCO}_{3} \text { solution }\end{aligned}$

Ether layer

washed with water concentrated

Fraction $\mathrm{X}$

containing

PE, PP, PB \& DLC

hydrolyzed with $\mathrm{NaOH}$ solution acidified with $\mathrm{HCl}$ extracted with ether

Fraction $Z$

containing

PA \& DLC

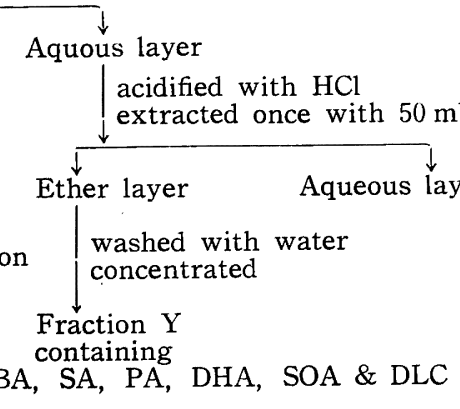

Thin layer chromatography

\begin{tabular}{l|c|c} 
Fraction & Adsorbent & Solvent \\
\hline For group separation \\
X, Y & A or B & I \\
\hline \multicolumn{2}{|c}{ For detection of individuals } \\
Y & B & II \\
& A or B & III \\
Z & B & II
\end{tabular}

Fig. 1. A scheme of separation of food preservatives and dulcin in foods 
フラクションX，Yをそれぞれェタノール $5 \mathrm{ml}$ に溶 解し, 内径約 $1 \mathrm{~mm}$ 毛細管で薄層を剝離しないように 径 2〜 $3 \mathrm{~mm}$ 法ポットし，さらに同じプレート上に対 照品の $0.1 \%$ エタノール液をつけて，溶媒Ｉで展開する と, PA 以外の酸性保存料は Rf $0.9 \sim 1.00$ 位置に, パ

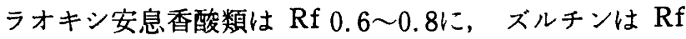
0.4 に検出された.

PA 以外の酸性保存料の存在が考えられるときは, 吸 着剂 B と溶媒IIおよび吸着剤 $\mathrm{A}$ と溶媒亚により展開し， 対照品の Rf 值と比較して判定した。

パラオキシ安息香酸エステル類の存在が考えられると きは, フラクションXの一部を加水分解し, フラクショ ンZとする. フラクションXとZならびにェステル類と PA の対照品とを並行展開して確認した。

ズルチンは溶媒Ｉおよび而で展開して確認することが できた。

以上の方法でみそ漬, かす漬, きざみ漬, 乳酸菌领料 から DHA，きざみ漬，煮豆から SOA， みそ漬，らっ きょ了漬, 海茸潰, 奨油からエステル類および乳酸菌飲 からズルチンが検出された。

\section{耛論}

保存料 (BA, SA, PA, PE, PP, PB, DHA, SOA) およびズルチンを薄層クロマトグラフィーにより分離㭥 出を試み,つぎの結果を得た。

1. 同じプレート上に発色剂として $1 \%$ 塩化第二鉄 溶液, BCG 溶液および $1 \%$ 過マンガン酸カリウム溶液 を続けて噴霧することにより精度よく各保存料およびズ ルチンを検出することができた。

2.クロロホルムープロピオン酸 $(4: 1)$ を用いて展 開し, PA 以外の酸性保存料 (BA, SA, DHA, SOA), パラオキシ安息香酸ならびにそのェステル類 $(\mathrm{PA}, \mathrm{PE}$, $\mathrm{PP}, \mathrm{PB})$ およびズルチンに大別し，クロロホルム醀酸
エチル（9:1) および $n$-ヘプタンープロピオン酸 (4: 1）で展開し，各保存料およびズルチンをそれぞれ分離 確認した。

3. PA の定性反応である Millon-Lintner 反応はズ ルチンでも紅色を呈し，食品にパラオキシ安息香酸エス テル類とズルチンが併用されている場合，あるいはズル チン単独でも PAの判定に疑問を生ぜしめるが, 著者ら の方法で容易に分離検出できた。

4. 以上の方法で食品中の保存料およびズルチンを系 統的に容易に検出することができた.

終りに臨み，本研究を行なう機会を与えられ，また終 始ご支援を賜わった長崎県衛生研究所 高橋克巳所長に 深謝する.

本報の概要は, 第20回日本楽学大大会（昭利 40 年 4 月 7 日, 福岡市) で発表.

文献

1）菰田太郎，竹下隆三 : 食衛誌. 2, No. 4, 72 (1961).

2）菰田太郎，竹下隆三：食衛誌．3，374 (1962).

3）菰田太郎, 竹下隆三, 他: 第17回日本薬学大会発 表 43 59 (1963).

4）菅野三郎, 他：第17回日本薬学大会発表 $43 \sim 64$ (1963).

5）菇田太郎，竹下隆三：第19回日本薬学大会発表 $6 \mathrm{I}, 51$ (1964).

6) J. W. Copuis-Peereboom, H. W. Beekes: J. Chromatog. 4, 417 (1964).

7) H. Ganshirt, K. Morianz: Arch. Pharm. 293, 1065 (1964).

8) K. Randerath: "Dunschicht Chromatographie" p. 175, 163 (1963), Verlag Chemie, Academic. 